\title{
RESENHAS RBEP
}

http://dx.doi.org/10.1590/S2176-6681/373813678

\section{Educação comparada e o mundo globalizado}

Robert E. Verhine

COWEN, Robert; KAZIMIAS, Andreas M.; UNTERHALTER, Elaine

(Org.). Educação comparada: panorama internacional e perspectivas.

Brasília, DF: Unesco/Capes, 2012. 772 p. v. 2.

Diante do mundo globalizado, torna-se necessário o entendimento de perspectivas diferentes, oriundas de culturas distintas, e também a promoção de novos conhecimentos e ideias, para aperfeiçoar práticas e políticas educacionais e para formular teorias e generalizações a respeito das múltiplas interações entre educação e sociedade. São imprescindíveis, portanto, estudos, debates e relatos de experiência, oriundos do campo de conhecimento denominado "educação comparada". A importância da educação comparada para os que se envolvem na pesquisa, na política e na prática educacional é evidenciada por suas três dimensões estruturantes. Uma, de natureza científica, busca construir teoria sobre as interfaces existentes; outra, de cunho pragmático, tenta identificar lições de iniciativas educacionais desenvolvidas em outros países para a melhoria de políticas e práticas locais; e a terceira, de foco internacional, leva à compreensão de 
outras culturas e nações para promover intercâmbios e a paz no âmbito internacional.

A educação comparada, como área específica de estudo, começou a se consolidar a partir da década de 1950, com o desenvolvimento de suas próprias teorias, metodologias, sociedades acadêmicas, periódicos e programas de pós-graduação. No Brasil, foram produzidos trabalhos importantes de educação comparada por autores tais como Rui Barbosa, Anísio Teixeira e, especialmente, Lourenço Filho.

Até 1980, a maioria das faculdades de educação oferecia uma disciplina sobre o assunto. Porém, no início da década de 1980, como reação contra o governo militar e sua política de internacionalização "dependente", houve uma tendência, por parte da comunidade acadêmica brasileira, a rejeitar modelos do exterior, especialmente os dos países do chamado "primeiro mundo". Assim, a educação comparada perdeu espaço e, em muitas instâncias, as disciplinas sobre o tópico foram retiradas do currículo dos cursos superiores de pedagogia. Como consequência, o número de professores especializados e/ou interessados na análise comparada de educação diminuiu significativamente.

Mais recentemente, diante da predominância dos processos associados à globalização e à internacionalização, o campo vem, paulatinamente, se ressuscitando no Brasil, porém, os avanços na área têm sido limitados pela falta de literatura em português, necessária para estimular e fundamentar estudos comparados e para sensibilizar e ensinar alunos de graduação e de pós-graduação a respeito do referido campo de conhecimento.

E neste contexto que se percebe a importância do recente lançamento, por meio de uma parceria entre a Coordenação de Aperfeiçoamento de Pessoal de Nível Superior (Capes) e a Organização das Nações Unidas para a Educação, a Ciência e a Cultura (Unesco), do segundo volume do livro Educação Comparada: panorama internacional e perspectivas, obra traduzida do inglês para o português e organizada por três estudiosos de renome internacional: Robert Cowen, do Instituto de Educação da Universidade de Londres (Reino Unido); Andreas M. Kazimias, da Universidade de WisconsinMadison (EUA) e da Universidade de Atenas (Grécia); e Elaine Unterhalter, também do Instituto de Educação da Universidade de Londres (Reino Unido).

O segundo volume, como o primeiro, é composto de 40 artigos, todos originais escritos especificamente para a referida coletânea por especialistas em educação de todo o mundo. Cada um dos dois volumes abrange mais do que 750 páginas e organiza os artigos de acordo com quatro agrupamentos distintos, porém complementares. No primeiro volume, as quatro seções são denominadas: (1) Criação e recriação de um campo de estudos; (2) Formações políticas e sistemas educacionais; (3) O nacional, o internacional e o global; e (4) Industrialização, economias do conhecimento e educação. As seções do segundo volume são intituladas: (1) Pós-colonialismo; (2) Culturas, conhecimento e pedagogias; (3) Uma nova maneira de pensar; e (4) Questionando o futuro. Algumas delas incluem capítulo de introdução e de conclusão e, no seu conjunto, tratam de um número enorme de assuntos, contemplando questões teóricas, pesquisas empíricas, revisões 
de literatura, análises históricas e reflexões sobre a situação educacional do presente e do futuro.

Muitos dos artigos são dirigidos ao campo específico da educação comparada, mapeando sua epistemologia, sua história e o conhecimento por ela produzido, discutindo e propondo alterações a respeito de seus conceitos, categorias de análise e de sua metodologia. Outros se orientam em função de um público mais abrangente, considerando, por um lado, tendências transnacionais, tais como a globalização, o modernismo, a democracia e o desenvolvimento socioeconômico, e, por outro lado, tópicos mais específicos, contemplando, por exemplo, a violência, a religião e os diferentes aspectos do processo educacional (gestão, ensino, aprendizagem etc.). O foco principal, obviamente, está na aplicação de análises comparativas, não apenas entre países, mas também entre outras unidades geográficas e conceituais, por exemplo, diferentes regiões, comunidades, escolas, políticas públicas e perspectivas teóricas.

Assim, o leitor do livro aprende sobre a disciplina da educação comparada e sobre seus resultados em termos de comparações concretas realizadas no contexto de um mundo globalizado. A abrangência dos assuntos tratados é indicada pelo fato de que, levando em conta apenas os títulos dos artigos que compõem o segundo volume, são mencionados os países: África do Sul, Argentina, China, Egito, Índia, Inglaterra, Japão, Coreia do Sul, Líbano, Turquia e, evidentemente, o Brasil (em dois artigos). Dentro dos textos, são abordados, comparativamente, muitos outros países, oferecendo, assim, uma visão internacional do fenômeno da educação, tanto estruturado quanto não estruturado.

Dessa forma, o livro é útil para pessoas que querem compreender a relação educação/sociedade, para pessoas que querem saber o que está acontecendo no campo da educação em outras partes do mundo e, ainda, para pessoas que querem efetuar suas próprias análises de cunho comparativo.

As contribuições do livro para a melhoria da educação no Brasil são múltiplas. Por exemplo, em relação à problemática do currículo escolar, o artigo "A reforma curricular na Africa Subsaariana: quando o local encontra o global", de Linda Chisholm e Ramon Lyendecker, é valioso, pois, ao tratar de reformas curriculares na África, mostra a tensão existente entre duas tendências gerais: o foco na criança e o foco nos resultados. No Brasil, o foco na criança é enfatizado desde a década de 1930, mas o foco nos resultados é mais recente, associado à implementação de sistemas de avaliação em larga escala a partir da década de 1990. As duas tendências são válidas, embora aparentemente contraditórias. Segundo os mencionados autores, os conceitos, bem como as pretensões associadas com as referidas tendências, têm de ser esclarecidos entre os que participam do campo da educação para que suas complementariedades possam se fortalecer.

Outros artigos que tratam do currículo incluem dois escritos por Andreas Kaziamias intitulados "O conhecimento educacional: um tema negligenciado na educação comparada" e "Agamenon contra Prometeu: globalização, sociedades de conhecimento/da aprendizagem e paideia na 
nova cosmópole". O referido autor ressalta que o foco atual no racional, técnico, científico e instrumental, ligado a noções neoliberais sobre a centralidade do mercado, pode prejudicar a cultura liberal, com sua ênfase nas humanidades, nas artes e na "vida da mente". Defende um currículo "humanístico" que inclui idiomas, literatura, poesia, drama, filosofia, história, música e artes. A visão dele do currículo vai além do humanismo clássico, pois defende que sejam tratados temas da atualidade, como pobreza, gênero e racismo.

Fica evidente que as reformas curriculares precisam ser articuladas com os avanços no campo da pedagogia. Senão, tais reformas ficam apenas no papel e não na prática, pois é por meio da pedagogia que o currículo torna-se vivo e implementável. Enquanto Andreas Kaziamias discute uma pedagogia humanística que complemente suas noções referentes a um currículo humanístico, Andy Hargreaves, no artigo "Mudança pedagógica e educacional para sociedades do conhecimento sustentáveis", apresenta a ideia de uma pedagogia sustentável, que focaliza a habilidade de aprender e inovar, por um lado, e a preservação de visões históricas e culturais, por outro. O autor considera que a pedagogia deve levar em conta não apenas o novo conhecimento, mas também o conhecimento já construído, nativo e de longo prazo.

Em relação à pedagogia, dois artigos do livro abordam a chamada "pedagogia crítica". O artigo "Política teoria e realidade na pedagogia crítica", de Michael Apple e Wayne Au, argumenta que a pedagogia crítica deve ser preservada e aperfeiçoada e, para isso, fornece informações preciosas sobre sua história, literatura e desafios.

O trabalho "Reinventando espaços educacionais, construindo uma cidadania atuante: duas experiências brasileiras", de Tristan McCowan e Luis Armando Gandin, por sua vez, trata das contribuições de Paulo Freire e das experiências educativas do Movimento dos Trabalhadores Rurais Sem Terra (MST) e da Escola Cidadã, em Porto Alegre. O artigo é notável, pois, além de defender a perspectiva de uma pedagogia crítica, também revela algumas de suas limitações e problemas. Ressalta, por exemplo, a questão da sustentabilidade das experiências brasileiras com a pedagogia crítica, pois o MST transformou-se a partir de sua associação com o governo do Partido dos Trabalhadores (PT) e a Escola Cidadã não sobreviveu a mudanças políticas/eleitorais na gestão da cidade na qual se situou.

O tema multiculturalismo é fortemente relacionado à questão do currículo e da pedagogia. O artigo "O futuro dos estudos interculturais nas sociedades multiculturais", de Jagdish Gundara, trata do assunto, defendendo que sejam valorizadas as diferenças culturais de forma a permitir a construção de uma sociedade coesa, baseada em valores compartilhados. Seu trabalho focaliza sociedades multilinguais, com diferenças culturais muito mais fortes do que no caso brasileiro, porém, a questão das diferenças, especialmente em termos econômicos e raciais, também permeia o Brasil. Nesse sentido, o artigo sugere estratégias relevantes ao advogar uma educação inclusiva e um currículo compartilhado. Fica evidente que, na opinião do autor, o foco no multiculturalismo deve começar nos anos iniciais 
de escolaridade e receber atenção especial na formação de professores. A respeito da ação afirmativa, o autor acredita que deve ser cuidadosamente planejada, atingir grupos realmente menos favorecidos e ter um limite de vigência preestabelecido. Segundo ele, caso tais requisitos não sejam atendidos, políticas em prol de grupos minoritários podem exacerbar tensões e reduzir o sentido de "comunalidade" entre diferentes segmentos da sociedade.

Na mesma linha, dois dos textos que compõem o livro confrontam a questão do gênero. O capítulo "Gênero e educação em contextos de países em desenvolvimento: reflexões pós-coloniais sobre a África", de Deevia Bhana, Robert Morrell e Rob Pattman, e o capítulo "Feminismo, libertação e educação", de Nelly Stromquist, mostram que o problema de gênero é especialmente sério em países africanos e islâmicos, mas que ainda existe no Brasil, particularmente em relação aos salários no mundo do trabalho e às escolhas no mundo da educação. Entre essas, destaca-se a escolha de ser ou não ser um professor de educação fundamental. Percebe-se que a inclusão do sexo masculino no ensino fundamental é importante, pois valoriza não apenas o ensino, mas também o sexo feminino, que deixaria de ser "relegado" a uma profissão considerada secundária, vista como sendo apropriada para a mulher por se aproximar do seu papel de mãe ou de tia.

Um último exemplo de um assunto importante tratado pelo livro são as novas tecnologias e suas relações com a educação. No artigo intitulado "Tecnologia digital e educação: contexto, pedagogia e relações sociais", seu autor, Andrew Brown, aponta que a tecnologia não necessariamente transforma os procedimentos pedagógicos ou o papel do professor, sua efetivação depende do contexto na qual se insere. Segundo o autor, são ainda remotas as condições de apropriação e utilização produtivas das tecnologias digitais. Neste sentido, são necessários investimentos institucionais, flexibilidade por parte dos órgãos de controle, mudanças nas expectativas dos alunos e reformas nas práticas do professor.

Em suma, o volume 2 do livro Educação Comparada: panorama internacional e perspectivas, em conjunto com seu volume 1, fornece subsídios preciosos para pesquisadores, professores e estudantes no Brasil e em qualquer outro país de origem lusa. Ele contribui para que, nesses países, a educação comparada possa atingir seus cinco objetivos principais, quais sejam: (1) promover conhecimento sobre o outro; (2) promover conhecimento sobre si mesmo; (3) divulgar experiências de outros contextos para fins de reflexão e inspiração; (4) estimular intercâmbios e cooperação internacional (fortalecendo tendência em prol da paz); e (5) formular e aperfeiçoar teorias a respeito da relação entre educação e sociedade.

Robert E. Verhine, doutor em Educação pela Universität Hamburg (Alemanha), é professor associado da Faculdade de Educação da Universidade Federal da Bahia (UFBa), Salvador, Bahia, Brasil.

verhine@ufba.br 